\title{
A novel passive microfluidic device for preprocessing whole blood for point of care diagnostics
}

Shah, Pranjul Jaykumar; Dimaki, Maria; Svendsen, Winnie Edith

Published in:

International Solid-State Sensors, Actuators and Microsystems Conference, 2009. TRANSDUCERS 2009.

Link to article, DOI:

10.1109/SENSOR.2009.5285475

Publication date:

2009

Document Version

Publisher's PDF, also known as Version of record

Link back to DTU Orbit

Citation (APA):

Shah, P. J., Dimaki, M., \& Svendsen, W. E. (2009). A novel passive microfluidic device for preprocessing whole blood for point of care diagnostics. In International Solid-State Sensors, Actuators and Microsystems

Conference, 2009. TRANSDUCERS 2009. IEEE. https://doi.org/10.1109/SENSOR.2009.5285475

\section{General rights}

Copyright and moral rights for the publications made accessible in the public portal are retained by the authors and/or other copyright owners and it is a condition of accessing publications that users recognise and abide by the legal requirements associated with these rights.

- Users may download and print one copy of any publication from the public portal for the purpose of private study or research.

- You may not further distribute the material or use it for any profit-making activity or commercial gain

- You may freely distribute the URL identifying the publication in the public portal 


\title{
A NOVEL PASSIVE MICROFLUIDIC DEVICE FOR PREPROCESSING WHOLE BLOOD FOR POINT OF CARE DIAGNOSTICS
}

\author{
P. J. Shah , M. Dimaki and W. E. Svendsen ${ }^{1}$ \\ ${ }^{1}$ DTU NANOTECH, Department of Micro and Nanotechnology, DTU, Denmark
}

\begin{abstract}
A novel strategy to sort the cells of interest (White Blood Cells (leukocytes)) by selectively lysing the Red Blood Cells (erythrocytes) in a miniaturized microfluidic device is presented. Various methods to lyse cells on a chip exist i.e. electrical, mechanical, chemical and thermal but they need integration of electrodes, traps, reservoirs, heaters, etc which is often difficult at microscale [1 - 4]. On the other hand, FACSlyse protocol uses only osmotic pressure to lyse erythrocytes allowing further isolation of leukocytes. This motivated us to develop a novel herringbone based lyser which works on the principle of mixing whole blood with pure water in time controlled manner to lyse erythrocytes osmotically on a chip.
\end{abstract}

\section{KEYWORDS}

Blood Processing, Microfluidics, Leukocytes Isolation, Mixers, Rapid prototyping.

\section{INTRODUCTION}

While herringbone mixers have previously been used for lysing erythrocytes [5], there have been several attempts to optimize the design in order to improve the time of lysing, time of fabrication and mostly the size reduction of the actual mixing device. Sethu et. al.[5] have reported a microfluidic device which could achieve lysing of erythrocytes using herringbone mixers of $15-80 \mathrm{~cm}$ mixing length and takes about $15-40 \mathrm{~s}$. We have modified the herringbone mixer design to optimize the mixing operation and achieve the lysing in fewer than $15 \mathrm{~s}$ and using only $8 \mathrm{~cm}$ mixing length [Fig. 1]. Also utilizing rapid prototyping laser ablation process our devices are prepared cleanroom free and are realized in less than 2 hours. While other groups have achieved lysing of erythrocytes, there still remain problems involving isolation of the leukocytes from cell debris on a chip. In our chip, we have integrated a pinch flow fractionation segment in the lyser to sort the cell debris from leukocytes [Fig. 2]. Current and future work is targeted to modify this device into a gravitational lysing column which will work as a standalone unit requiring no external input (i.e. syringe pumps).

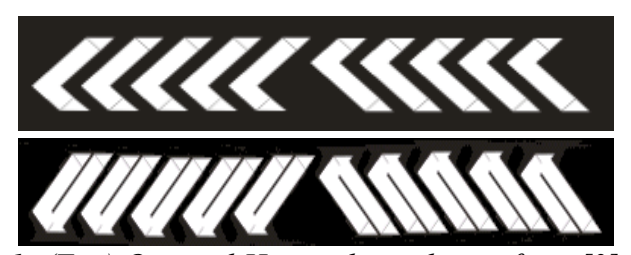

Figure 1: (Top) Original Herringbone design from [3] (Bottom) Modified Design.

\section{PRINCIPLE OF HERRINGBONE LYSERS}

The herringbone based lyser works on the principle of mixing whole blood with lysis solution in a time controlled fashion to selectively lyse erythrocytes. The erythocytes lyse faster than leukocytes (under 12s) when exposed to water and this process of osmotic lysing is used to achieve an isolation of leukocytes which only get lysed if exposed longer to water or lysing solution. Upon lysing the erythrocytes, hence the unlysed leukocytes are mixed with PBS buffer solution to normalize them and later these leukocytes are sorted from the debris using pinch flow fractionation [6]. The entire integrated chip works seamlessly without any external inputs other than blood and processing fluids.

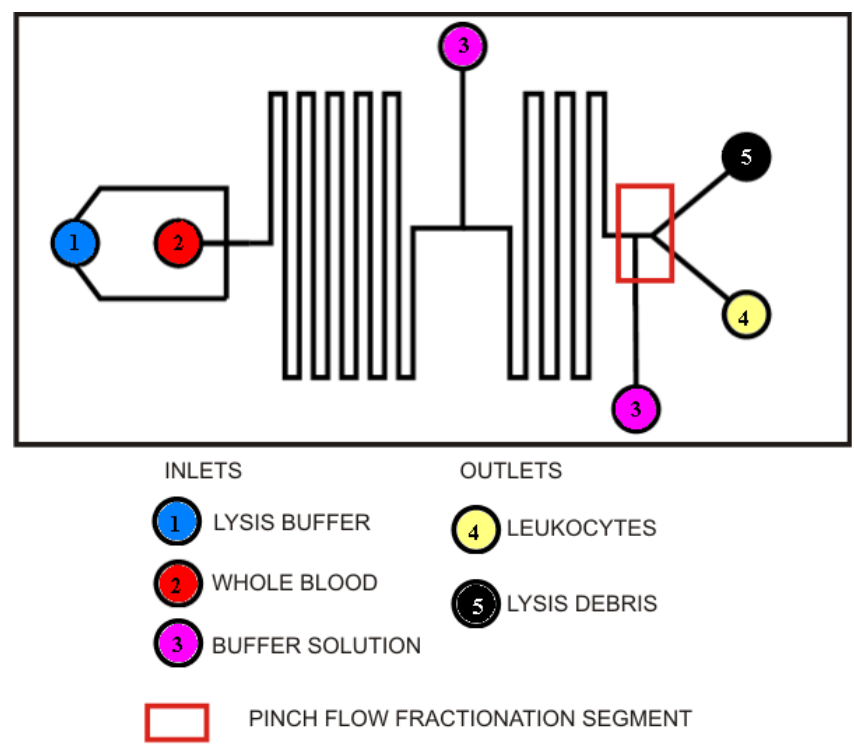

Figure 2. Schematic of the integrated device to simultaneously lyse erythrocytes and isolate leukocytes using pinch flow fractionation segment. 


\section{SIMULATIONS}

We have optimized the mixing by modifying the herringbone design which was simulated and compared with previously published micromixers. COMSOL simulations of these designs show significant improvement in the mixing efficiency [Fig. 3, 4].The optimization of the herringbone design was based on spatial considerations to improve the transverse flow in otherwise laminar flow microchannel. The simulations and subsequent experiments have shown that our design improves mixing efficiency by $40 \%$. The vorticity plot comparisons of our design [7] and Stroock's design [8] confirm that the chaos in the flow can be improved by optimizing the herringbone design.

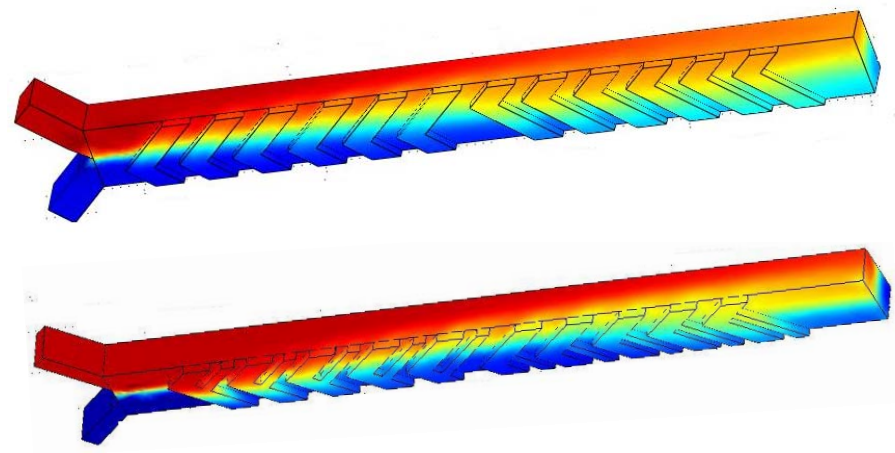

Figure 3. (Top) Mixing in Stroock's Herringbone mixer (Bottom) Mixing in our Herringbone mixer. In both, the figures Red colour illustrates Blood and Blue illustrates Lysing solution.
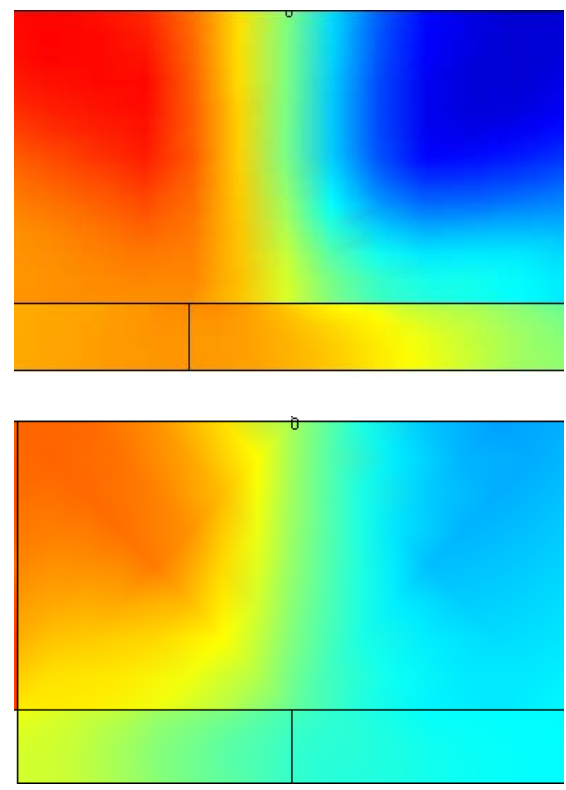

Figure 4. Profile of mixing at the outlet after one cycle of Stroock's mixer (Top) and our mixer (Bottom).

\section{FABRICATION}

\section{$\mathrm{CO}_{2}$ Laser Ablation process}

Laser ablation process was used to realize these devices to avoid cleanroom access and reduce the fabrication time to fewer than 120 mins. The device was fabricated using a $\mathrm{CO} 2$ laser in polymethylmethacrylate (PMMA) substrates [Fig. 5]. Firstly layer with channels, inlets and outlets were ablated which were followed by the herringbones which were ablated into the channels (herringbones dimension $\sim 250 \mu \mathrm{m}$ ).

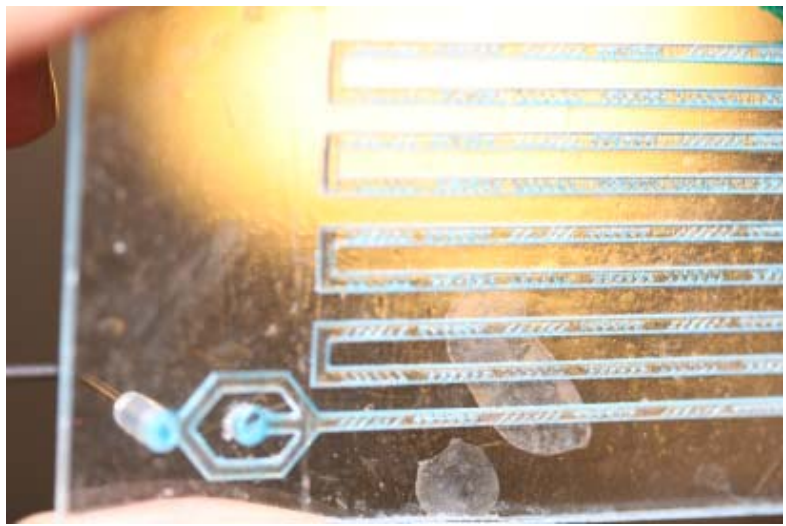

Figure 5. Laser ablated mixer on PMMA.

\section{Bonding \& Interconnects}

To seal the device another PMMA substrate was used a lid. The channels and lids surface were activated using $\mathrm{UV}$ radiation and were bonded in an oven at $108^{\circ} \mathrm{C}$ for 90 mins. The interconnects were created using Teflon tubings and needles (20 gauge).

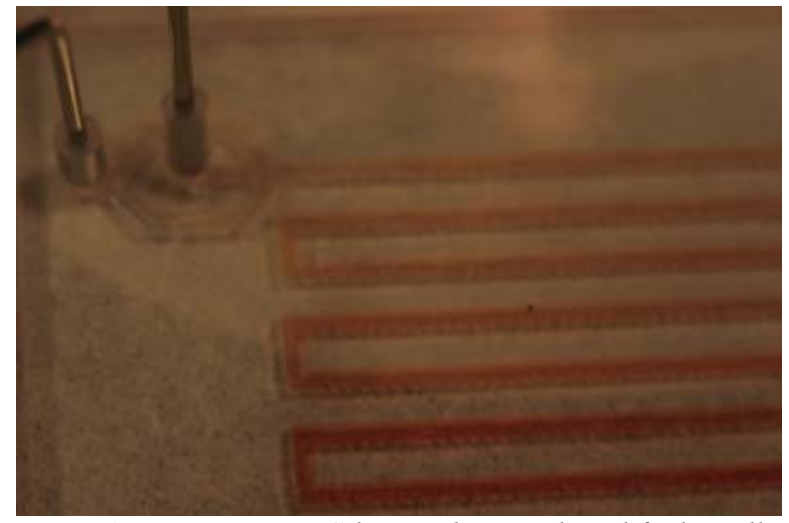

Figure 6. Interconnects: Silicon tubing and modified needles.

\section{RESULTS AND DISCUSSION}

The device was tested with whole blood and experiments confirm the improvement in mixing and blood lysing efficiency [Fig. 7, 8]. 


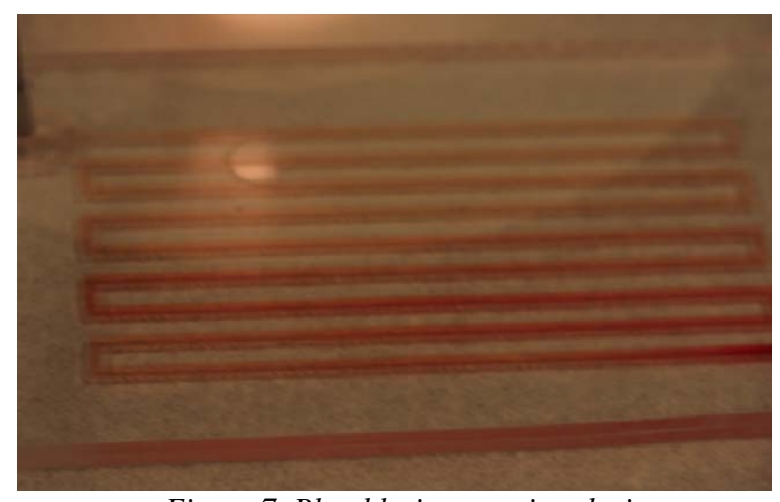

Figure 7. Blood lysing on microdevice.
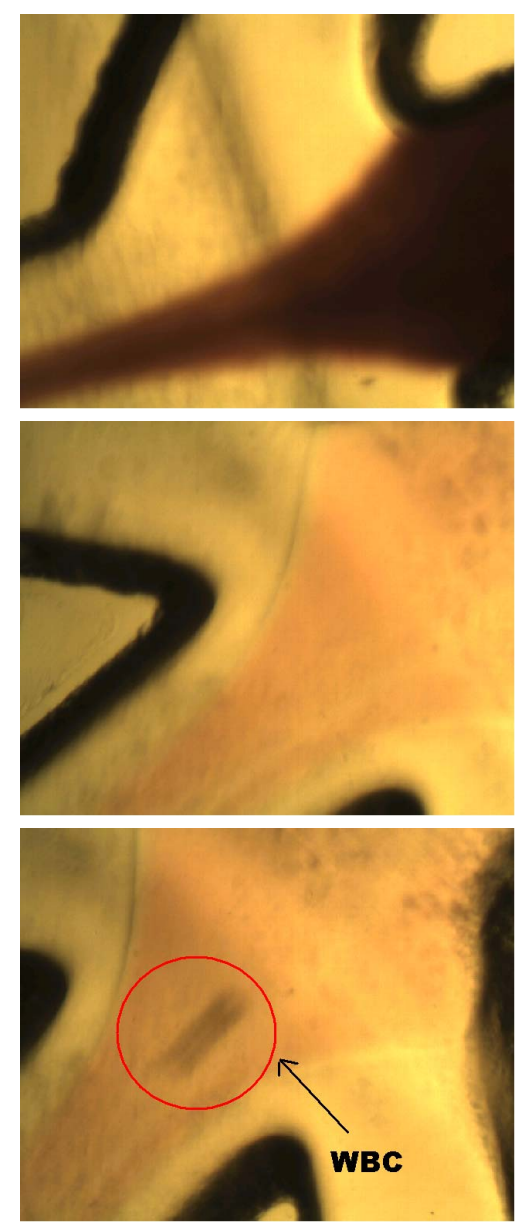

Figure 8. (Top) Blood entering inlet with lysing solution side streams (Middle) Outlet with no Red blood cells.(Bottom) WBC exiting at the Outlet.

The leukocytes collected from the outlet were stained with Trypan blue to verify the viability of the method [Fig. 9]. Later, smears of the cells collected at the outlet were stained with Giemsa solution to verify the lysing of erythrocytes.

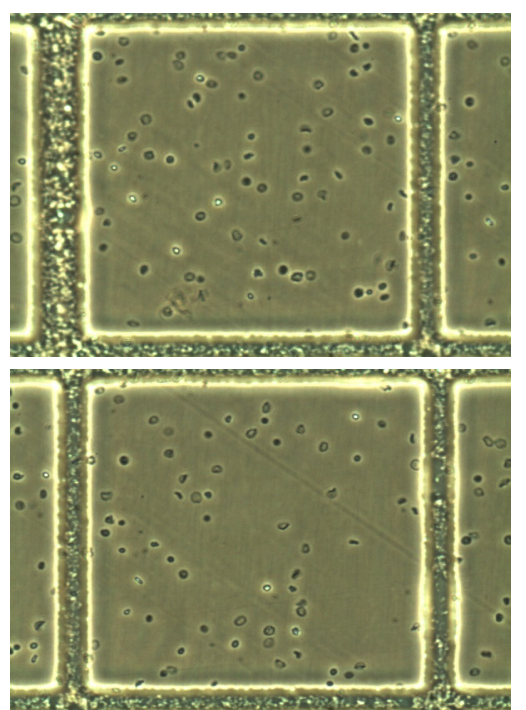

Figure 9. Cells stained with Trypan blue to check for viability of method for leukocyte isolation.

\section{GRAVITIONAL LYSING COLUMN}

Our passive principle of lysing erythrocytes and isolation of leukocytes has led to a new concept of gravitional lysing and leukocytes isolation column. Initially we aimed at using gravity as an actuation source for blood and lysing solution to achieve a standalone device [Fig 10].

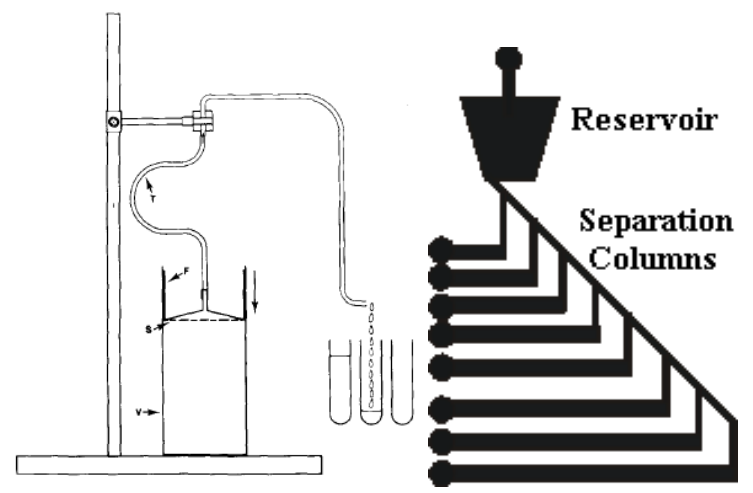

Figure 10. (Left) Original setup used for fractionation of blood and isolation of lymphocytes and monocytes. (Right) Schematic of the fractionation setup on a microchip.

Recently, we have rediscovered a technique widely used in the past but not much known today of enhanced separation of blood cells in a column under effect of gravity. In the $18^{\text {th }}$ century, it was discovered that different blood cells sediment at a different rate and this rate is different in males, females and often changes with respect to a particular disease. This is the basis of the Westergreen test [9] which was utilized in the past to diagnose patients for various diseases based on the time taken by erythrocytes to sediment called the Erythrocytes Sedimentation Rate (ESR)[10]. We have utilized this theory of differential sedimentation [11] of blood cells in 
whole blood fraction to achieve an enhanced lysing and separation of leukocytes in our lysing device. This device takes into consideration and benefits from the ESR and partially related leukocyte anti-sedimentation rate [12] for achieving a fractionation of the whole blood input using a gravitational fractionation device [Fig. 11].

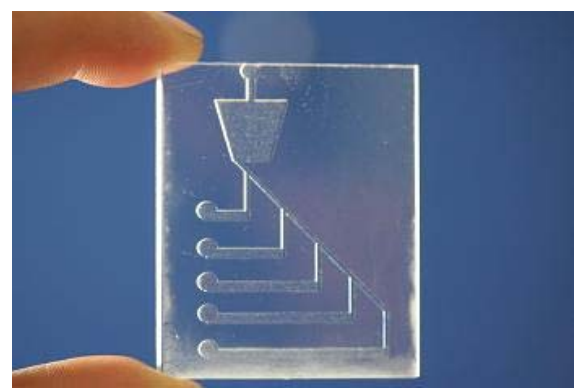

Figure 11. Microfluidic gravitional sedimentation device fabricated using laser ablation process in PMMA. This was the first version which has been modified to 8 column design.

In this device, the reservoir is maintained with lysing buffer for erythrocytes by a closed valve (A) isolating the reservoir from fractionation columns (1-5). The blood is added to the reservoir and allowed to sediment for few minutes. This leads to a fractionation of the blood cells in the reservoir, whereby the erythrocytes sediment faster through the lysing solution column and get lysed in the process. This downward flux on erythrocytes partially pushes the leukocytes upwards causing them to sediment relatively slower. This leads to an erythrocyte free zone right at the top of the column.

The valve is opened when the first erythrocytes near the bottom of the reservoir. Hence, when the reservoir valve is opened, it starts to fill up columns 1 to 8 in the same order due to the increasing hydraulic resistances. Initially, the unlysed erythrocytes and their debris will fill up the first few columns. This will be followed by columns containing the mixture of erythrocytes debris and leukocytes. Towards the end of the columns, the last columns should contain only fractions with leukocytes and essentially the last two columns should contain fractions enriched with lymphocytes and monocytes as they sediment the least.

\section{CONCLUSIONS}

We have developed a rapidly fabricated simple and efficient RBC lyser which can process whole blood and isolate Leukocytes for further downstream analysis. These micro mixers can be used for other reactions as they can be easily integrated on Lab-on-Chip systems and their passive mixing principle doesn't require any complex fabrication steps. The concept of an on-chip gravitational fractionation device was presented. Currently, this device is being fabricated and tested to utilize gravity for actuation and enhancing isolation. When realized this will be the first passive device achieving on-chip gravity based separation for isolating leukocyte and targeting leukocyte subtype populations. i.e. lymphocytes and monocytes. We envisage the applications of this device in clinical genetics, diagnostics and for pre-processing whole blood for lab on chip systems.

\section{REFERENCES}

[1] S.W. Lee, Y. Tai, "A micro cell lysis device," Sensors and Actuators, vol. 73,pp. 74-79, 1999.

[2] L. Gang, X. Hong, G. Min, C. Jing, "Miniaturized cell lysis device using spherically focused ultrasound," $J$. of Tsinghua University, China, Vol.8 Issue.4, pp. 48792, 2003.

[3] J. Kim, J. She-Hee, Z. Da Silva, A. Nancy, M. Madou, "Reagentless cell lysis on a PDMS CD using beads," Lab Chip, vol. 4, pp. 516-522, 2004.

[4] J. Hong Miao, et. al., "DNA purification silicon chip," Sensors and Actuators A, vol. 139, pp. 39-144, 2007.

[5] P. Sethu, M. Anahtar, L. L. Moldawer, R. G. Tompkins, M. Toner, "Continuous Flow Microfluidic Device for Rapid Erythrocyte Lysis Microfluidic Isolation of Leukocytes from Whole Blood for Phenotype and Gene Expression Analysis," Anal. Chem., vol.76, pp. 6247-6253, 2004.

[6] M. Yamada, M. Nakashima, M. Seki, "Pinched Flow Fractionation: Continuous Size Separation of Particles Utilizing a Laminar Flow Profile in a Pinched Microchannel," Anal. Chem., vol. 76, pp. 5465-5471, 2004.

[7] P. Shah, "Herringbone Lysers: Spatially Optimized microfluidic mixers to enhance lysing of red blood cells in water," in Digest NanoBioEurope'08 Conference, Barcelona, June 9-13, 2008, pg. 159.

[8] A. D. Stroock, S. K. W. Dertinger, A. Ajdari, I. Mezi, H.A. Stone, G. M. Whitesides, "Chaotic Mixer for Microchannels," Science, New Series, Vol. 295, No. 5555, , pp. 647-651, 2002.

[9] A. Westergren, "Studies of the suspension stability of the blood in pulmonary tuberculosis," Acta medica Scandinavica, vol. 54, pp. 247-282, 1921.

[10] J. Olshaker, D. Jerrard, "The Eythrocyte Sedimentation Rate," J. of Emergency Medi., vol. 15, pp. 869874, 1997.

[11] E. Trowbridge, "The fluid mechanisms of blood: equilibrium and sedimentation," Clin. Phys. Physiol. M eas., vol. 3, pp. 249-265,1982.

[12] L. Bogar, P. Tarsoly, "Gravity sedimentation of leukocytes is partially independent from erythrocyte Sedimentation," Clin. Hemor. and Microcir., vol. 34, pp. 439-445, 2006.

\section{CONTACT}

* Pranjul Shah, email: Pranjul.Shah@ nanotech.dtu.dk 